\title{
MICROSTRUCTURE DEVELOPMENT AND THERMAL RESPONSE OF DELTA PROCESSED BILLET AND BAR FOR ALLOY 718
}

\author{
J.L. Russell ${ }^{1}$, M.L. Lasonde ${ }^{2}$, L.A. Jackman ${ }^{1}$ \\ ${ }^{1}$ ATI Allvac, an Allegheny Technologies Company \\ 2020 Ashcraft Avenue; Monroe, North Carolina 28110 USA \\ ${ }^{2}$ General Electric Aircraft Engines \\ 1000 Western Avenue; Lynn, Massachusetts 01910 USA
}

Keywords: 718, Delta Phase, Thermomechanical Processing

\begin{abstract}
Delta processing of alloy 718 billet and bar provides a means to achieve fine grain microstructures for input forging stock applied to the manufacture of rotating turbine engine components. For an optimum balance of properties in the finished part, however, it is necessary to understand the effect of thermomechanical processing on billet/bar delta phase and subsequent response to thermal exposure during heating for forging. This study investigated the effect of conversion process on delta phase present in 203 and $137 \mathrm{~mm} \varnothing$ billets, and $64 \mathrm{~mm} \varnothing$ bar. Analysis included characterization of delta phase at intermediate conversion preform, billet and bar product, and after thermal exposure in the $968^{\circ} \mathrm{C}-$ $1024^{\circ} \mathrm{C}$ temperature range.
\end{abstract}

\section{Introduction}

Alloy 718 is widely used for the manufacture of critical rotating components for aerospace applications. A wide range and balance of properties can be developed by tailoring the thermomechanical processing (TMP) as well as heat treatment of this alloy. Higher strengths and maximized fatigue capability are achieved by fine grain forge processing and direct age heat treatment.

To achieve a fine grain microstructure throughout the finished part, forging suppliers often require fine grain billet as input forging stock. This is especially true where complex configurations limit the amount of forging strain locally within specific areas of the forging and for small diameter bore disks where mult end "die chilling" effects can "lock-in" billet microstructure. The grain size for larger diameter billet $(203 \mathrm{~mm}-305 \mathrm{~mm} \varnothing)$ often varies from surface to center with typical surface, mid-radius, and center grain sizes of ASTM 10, 8 , and 6 , respectively.

An alternate TMP approach to achieve a uniform grain size throughout the billet is delta processing. After initial ingot breakdown to an intermediate billet diameter, the billet is thermally cycled in the $843^{\circ} \mathrm{C}-899^{\circ} \mathrm{C}$ range to precipitate a high volume fraction of acicular delta phase $(\delta)$. Recrystalization during subsequent thermomechanical working below the $\delta$ solvus promotes a uniform fine grain structure and the acicular $\delta$ morphology becomes more spherical, restricting grain growth. 
Delta processed billet has been successfully utilized to produce fine grain alloy 718 forgings and maximize low cycle fatigue capability [1,2]. Careful selection of forging temperatures is required, however, to control the $\delta$ volume fraction in the finished part. High volume fractions reduce the amount of niobium available for gamma double prime $(\gamma$ ") formation and can result in lower part strength and creep capability [3]. As a result, a study of the thermal response of delta processed billet/bar of various diameters was conducted to aid in the selection of forging temperatures and soak times to optimize finished part properties.

\section{Material and Processing}

Two forged products (203 and $137 \mathrm{~mm} \varnothing$ ) and one rolled product (64 mm ø) were evaluated to represent the spectrum of billet and bar sizes directed toward delta processed applications.

\section{Melting}

Each size was produced from a separate triple melted ingot $508 \mathrm{~mm}$ in diameter. Triple melting consists of vacuum induction melting (VIM) followed by electroslag remelting (ESR) and final vacuum arc melting (VAR). Chemistries of the three ingot products were very similar and were typical of alloy 718 applied to rotating aerospace components. Chemistries for selected elements are presented in Table I.

Table I. Billet and Bar Product Chemistry for Selected Elements

\begin{tabular}{|c|c|c|c|}
\hline \multirow{2}{*}{ Product Diameter $(\mathbf{m m})$} & \multicolumn{3}{|c|}{ Wt \% } \\
\cline { 2 - 4 } & $\mathbf{N b}+\mathbf{T a}$ & $\mathbf{N i}$ & $\mathbf{C}$ \\
\hline \hline 203 & 5.41 & 53.40 & 0.026 \\
\hline 137 & 5.40 & 54.03 & 0.024 \\
\hline 64 & 5.37 & 53.62 & 0.026 \\
\hline
\end{tabular}

The $\delta$ solvus temperature for each heat of material was determined using a Differential Thermal Analysis (DTA) technique. This method generates a thermogram plot of temperature versus temperature differential between the material of interest and a reference standard that are subjected to identical temperature regimes with controlled heating or cooling rates. The inflection point of the heating thermogram curve indicates the $\delta$ solvus temperature. DTA results for the three heats of material are presented in Table II; the small variations in temperatures are within the accuracy of the analytical technique.

Table II. $\delta$ Solvus Temperatures for Billet and Bar Products

\begin{tabular}{|c|c|}
\hline Product Diameter (mm) & $\delta$ Solvus Temperature \\
\hline \hline 203 & $1018^{\circ} \mathrm{C}$ \\
\hline 137 & $1022^{\circ} \mathrm{C}$ \\
\hline 64 & $1015^{\circ} \mathrm{C}$ \\
\hline
\end{tabular}




\section{Processing}

A standard homogenization practice was applied to all three ingots prior to conversion. Ingots were converted to fine grain billet by the following thermomechanical processing steps:

- Ingot breakdown on a press to intermediate size

- Delta precipitation heat treatment

- Press forge to preform for GFM

- GFM forge to final size

The GFM billet was rolled on a continuous mill to produce the bar product.

Press Forging. Ingots were initially forged on an open die press at temperatures above the $\delta$ solvus temperature for alloy 718 . At $406 \mathrm{~mm} \varnothing$ diameter, a $\delta$ precipitation heat treatment was performed at $899^{\circ} \mathrm{C}$; this heat treatment precipitates extensive amounts of acicular $\delta$ phase [1,2]. Subsequent forging on the press to begin spheroidization of $\delta$ phase was conducted at temperatures below the $\delta$ solvus. Billets were air cooled off the press.

GFM Forging. Spheroidization of $\delta$ phase was continued by GFM forging the pressed preform to final size. Temperatures were below the $\delta$ solvus temperature to restrict the amount of $\delta$ phase going back into solution.

Rolling. Billet forged to $137 \mathrm{~mm} \varnothing$ on the GFM was rolled to $64 \mathrm{~mm} \varnothing$ on Allvac's continuous rolling mill. The furnace temperature for rolling was also below the $\delta$ solvus but was higher than the furnace temperature for final GFM forging.

\section{Results}

To better understand the final billet/bar microstructure and $\delta$ morphology, the starting billet structure prior to GFM forging was characterized. A representative scanning electron microscope (SEM) image at the mid-radius location is shown in Figure 1. Average grain size at this intermediate size was uniform from surface to center and was rated as ASTM 7. The $\delta$ phase morphology was very acicular at this stage of reduction and was semi-continuous at both grain and twin boundaries.

As-forged and as-rolled billet and bar microstructures were also documented and are included in Figure 1 for the mid-radius location. The 203 and $137 \mathrm{~mm} \varnothing$ billets exhibited a uniform grain size from surface to center of ASTM 10 and 11, respectively with $\delta$ phase significantly more spheroidal throughout the cross section than observed at the intermediate size (Figure 1). The $64 \mathrm{~mm} \varnothing$ bar, rolled on Allvac's continuous rolling mill, also exhibited an ASTM 10 or finer structure from surface to center. The volume fraction $\delta$ phase in the bar, however, was much less than observed in both billet diameters and the $\delta$ distribution was primarily at grain boundaries compared to grain and matrix for the billet. 


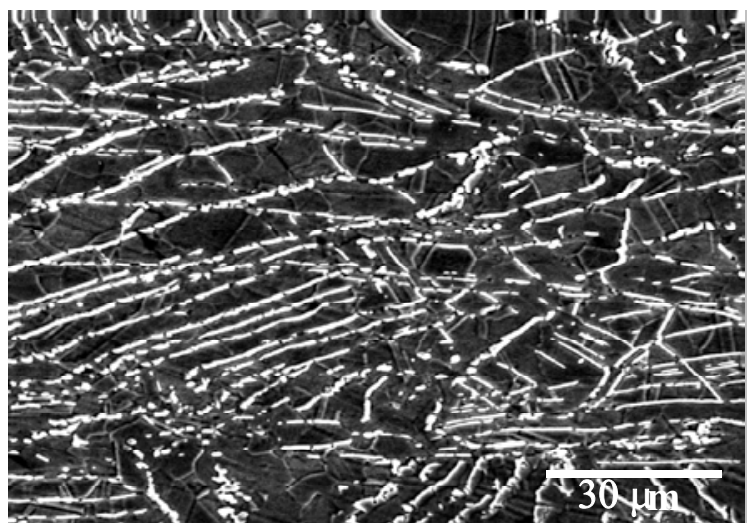

(a)

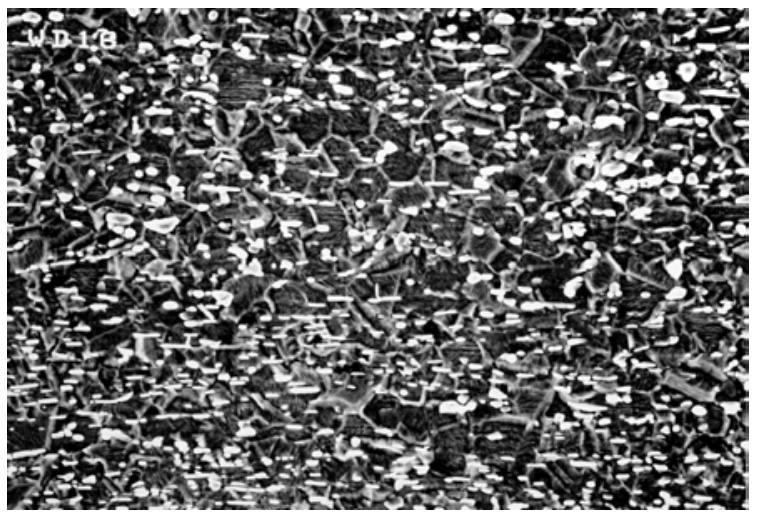

(c)

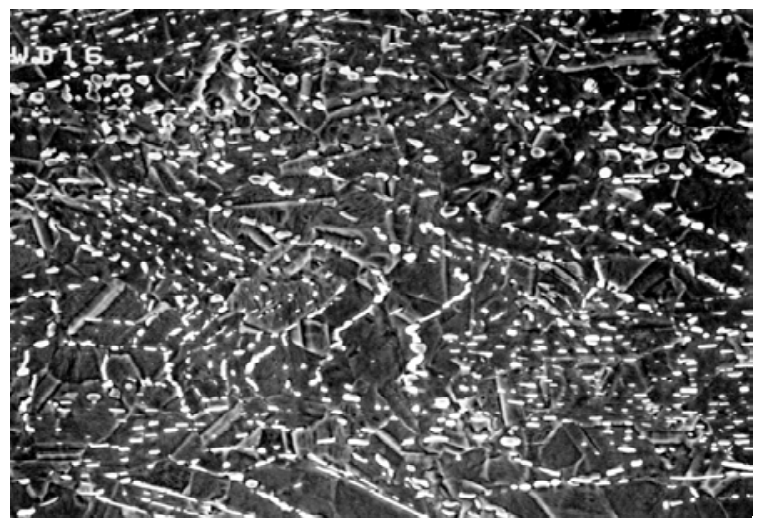

(b)

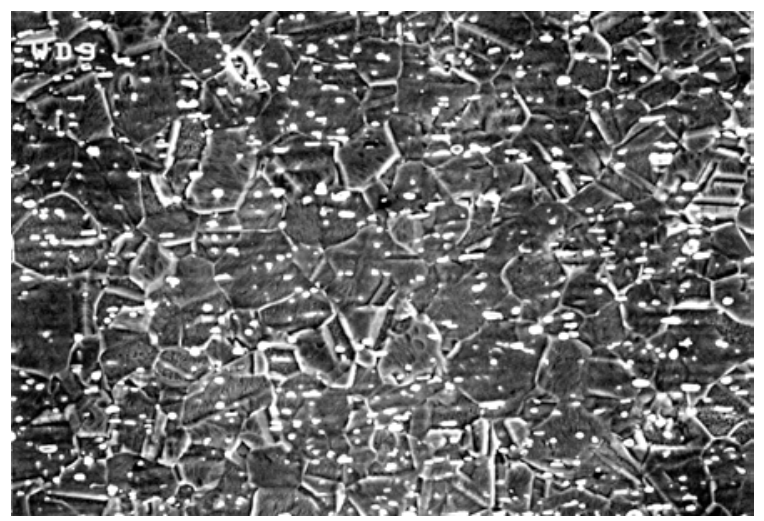

(d)

Figure 1. Microstructure at Mid-Radius Location for (a) Press Forged Preform, (b) and (c) As-GFM Forged Billet, and (d) As-Rolled Bar.

\section{$\underline{\text { Conversion Process Modeling }}$}

To aid in microstructural assessment, three dimensional finite element modeling was performed for press, GFM, and rolling operations. Temperature and strain profiles were determined for each forging pass as well as for each rolling stand. Temperature profiles during GFM and rolling for each of the three product sizes are shown in Figure 2 following the last heating operation. The saw tooth appearance of the GFM profiles reflects the adiabatic heating associated with each pass through the dies. There were three passes and two passes for the 203 and $137 \mathrm{~mm} \varnothing$ products, respectively. Surface temperatures were lower relative to temperatures at the center and mid-radius locations. This is expected because of surface heat losses during transfer from furnace to the GFM and heat losses during GFM forging including that due to die contact.

As illustrated in Figure 2, all predicted temperatures for both the 203 and $137 \mathrm{~mm} \varnothing$ billets were below the $\delta$ solvus temperature. In comparison, center temperature for the $64 \mathrm{~mm} \varnothing$ bar product was above the $\delta$ solvus through all roll stands. This rise in temperature for the rolled product can be attributed to fast rolling speeds that generate significant adiabatic heating. Also, the furnace temperature, although still below the $\delta$ solvus, was higher for rolling compared to GFM forging. 


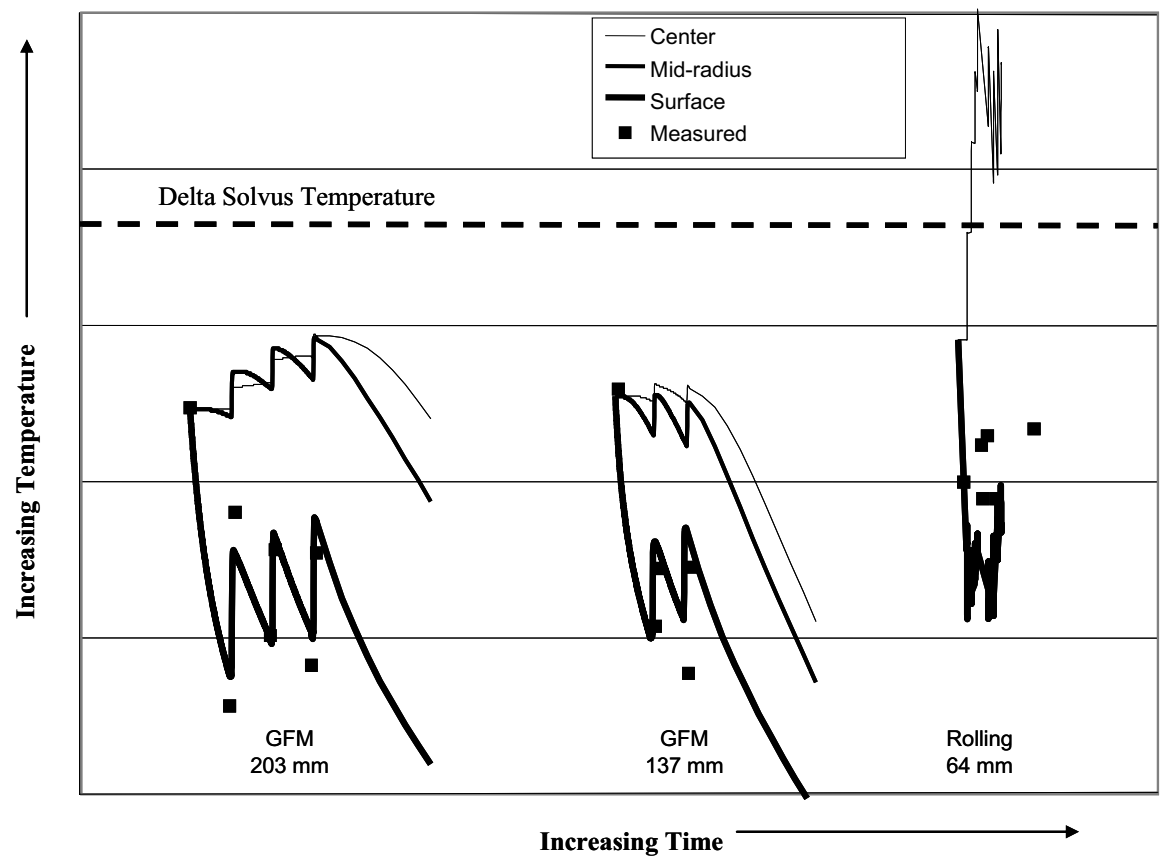

Figure 2. Predicted Temperature Profiles During GFM and Rolling Operations

\section{Thermal Exposure Study}

A thermal exposure study was conducted to characterize microstructural changes that occur during heating of delta processed billet for forging. For fine grain alloy 718 applications, closed die forging temperatures are often in the $982^{\circ} \mathrm{C}-1010^{\circ} \mathrm{C}$ range with furnace tolerance of $\pm 14^{\circ} \mathrm{C}$. Longitudinal samples were removed from the surface, midradius, and center of the three billet/bar sizes and heated in laboratory furnaces from $968^{\circ} \mathrm{C}$ to $1024^{\circ} \mathrm{C}$ in $14^{\circ} \mathrm{C}$ increments. Times at each temperature were $1,2,4$, and 8 hours to approximate the range of furnace soak times utilized in production, especially for finish forge operations.

\section{$\underline{\text { Grain Size Measurements }}$}

Grain size measurements were performed in accordance with ASTM E112 from longitudinal samples for the three billet/bar sizes at various radial locations from as-forged, as-rolled, and thermally cycled material. As-forged and as-rolled microstructures consisted primarily of equiaxed, recrystallized grains with uniform grain size from surface to center for all three diameter materials. Grain size was ASTM 10 for 203 and $64 \mathrm{~mm} \varnothing$ material compared to a slightly finer grain size of 11 for $137 \mathrm{~mm} \varnothing$ billet. Response to thermal exposure differed for each of the three material sizes. Grain size for $64 \mathrm{~mm} \varnothing$ bar remained fine at ASTM 10 until $1010^{\circ} \mathrm{C}$ as shown in Figure 3. At $1010^{\circ} \mathrm{C}$, a duplex structure developed which consisted of coarser bands with a grain size of about ASTM 7 in a matrix of ASTM 10 grains. The amount of coarse grains increased from less than $5 \%$ for one hour to $20 \%$ for four hours and $40 \%$ for eight hours at $1010^{\circ} \mathrm{C}$. Because of the duplex nature of this microstructure, grain sizes are not included in Figure 3. At $1024^{\circ} \mathrm{C}$, the structure was almost fully coarsened and continued to coarsen with increased time.

Grain sizes of as-forged billet became coarser with initial exposure time for both billet sizes $(137$ and $203 \mathrm{~mm} \varnothing)$ at $968^{\circ} \mathrm{C}$. The $203 \mathrm{~mm} \varnothing$ billet then remained stable until 8 hours at $996^{\circ} \mathrm{C}$ when it coarsened uniformly. After initial coarsening at $968^{\circ} \mathrm{C}$, grain size 
for the $137 \mathrm{~mm} \varnothing$ billet remained in the range of ASTM 8 to 9 through $996^{\circ} \mathrm{C}$ with a trend of slightly coarser structures with increasing exposure time. At $1010^{\circ} \mathrm{C}$, further coarsening occurred for both 137 and $203 \mathrm{~mm} \varnothing$; this was slightly time dependent for $137 \mathrm{~mm} \varnothing$ billet. Behavior at $1024^{\circ} \mathrm{C}$ was similar for both 137 and $203 \mathrm{~mm} \varnothing$ material with extensive time dependent coarsening taking place. All coarsening was uniform without duplexing for both 137 and $203 \mathrm{~mm}$ ø material.

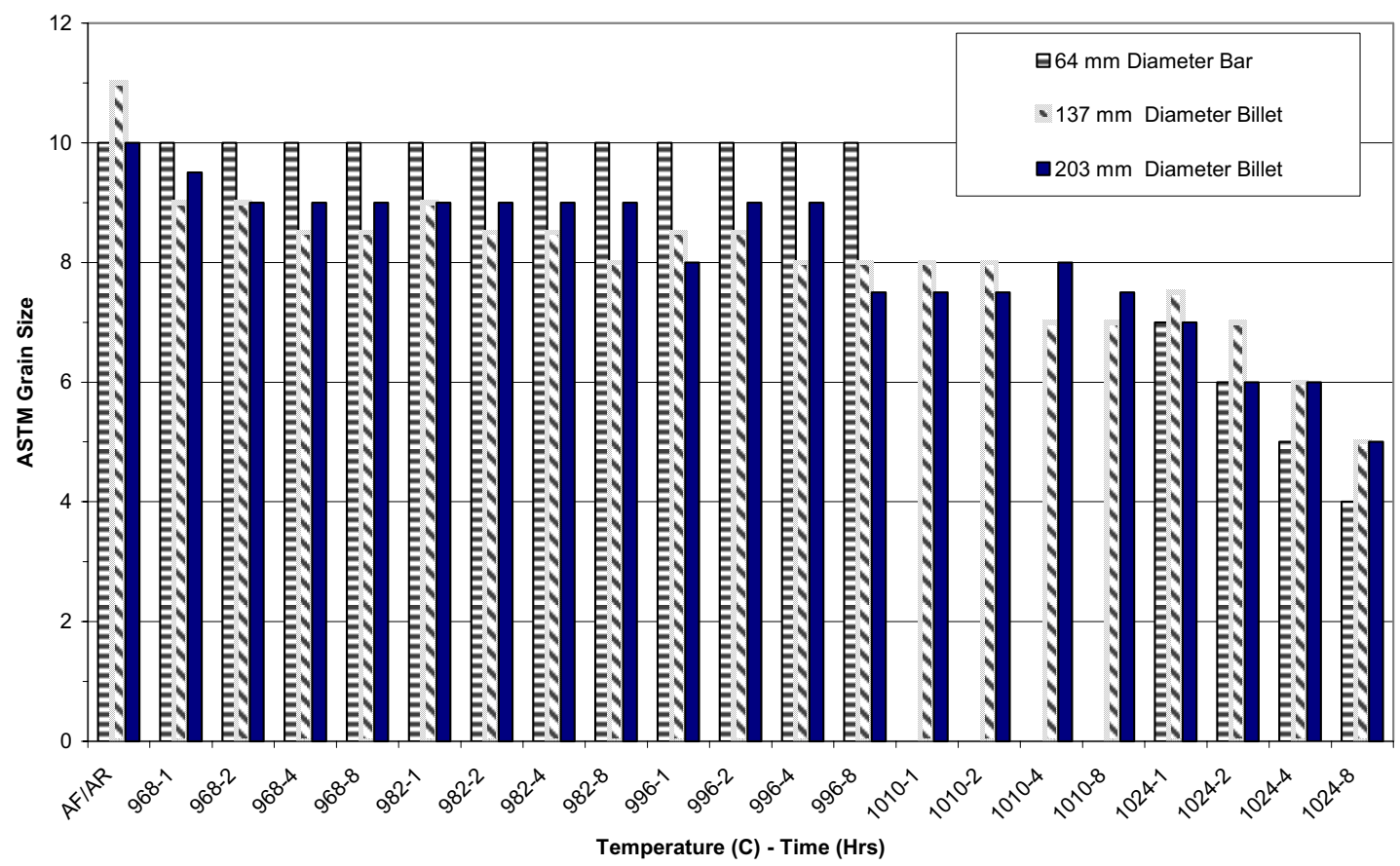

Figure 3. Grain Size as a Function of Thermal Exposure for Mid-Radius Location.

\section{Image Analysis}

Mid-radius longitudinal samples for each billet/bar size in the as-forged, as-rolled, and thermal cycled (4 hours) conditions were selected for image analysis. The samples were metallographically prepared and examined in the unetched condition using a JEOL 6400 scanning electron microscope in backscatter at $10-20 \mathrm{kv}$. A magnification of $1500 \mathrm{X}$ was selected and images were captured at six random locations for each sample to document the delta phase size, morphology, and distribution. Quantitative image analysis was performed using The Image Processing Tool Kit (v. 4.0) from Reindeer Graphics running with Photoshop as the software platform. Delta phase information collected and analyzed included \% delta, equivalent particle diameter, particle aspect ratio, and inter-particle spacing. Results for delta phase imaging are presented in Table III and representative post processed images for the $203 \mathrm{~mm} \varnothing$ billet are shown in Figure 4. 
Table III. Delta Phase Imaging Results

\begin{tabular}{|c|c|c|c|c|c|c|c|c|c|c|c|c|}
\hline & \multicolumn{4}{|c|}{203 mm Diameter Billet } & \multicolumn{4}{|c|}{137 mm Diameter Billet } & \multicolumn{4}{|c|}{$64 \mathrm{~mm}$ Diameter Bar } \\
\hline & $\begin{array}{l}\text { Percent } \\
\text { Delta }\end{array}$ & $\begin{array}{c}\text { Equivalent } \\
\text { Diameter } \\
\text { (Microns) }\end{array}$ & $\begin{array}{c}\text { Aspect } \\
\text { Ratio }\end{array}$ & $\begin{array}{c}\text { Interparticle } \\
\text { Spacing } \\
\text { (microns) }\end{array}$ & $\begin{array}{c}\text { Percent } \\
\text { Delta }\end{array}$ & $\begin{array}{c}\text { Equivalent } \\
\text { Diameter } \\
\text { (Microns) }\end{array}$ & $\begin{array}{c}\text { Aspect } \\
\text { Ratio }\end{array}$ & \begin{tabular}{|c} 
Interparticle \\
Spacing \\
(microns) \\
\end{tabular} & $\begin{array}{c}\text { Percent } \\
\text { Delta }\end{array}$ & $\begin{array}{c}\text { Equivalent } \\
\text { Diameter } \\
\text { (Microns) }\end{array}$ & $\begin{array}{c}\text { Aspect } \\
\text { Ratio }\end{array}$ & $\begin{array}{c}\text { Interparticle } \\
\text { Spacing } \\
\text { (microns) }\end{array}$ \\
\hline As-Forged/Rolled & 6.2 & 0.8 & 2.4 & 1.8 & 6.3 & 0.9 & 2.5 & 2.1 & 1.5 & 0.7 & 2.1 & 3.2 \\
\hline $968^{\circ} \mathrm{C}-4$ Hours & 5.4 & 0.7 & 2.3 & 1.8 & 4.6 & 0.7 & 2.6 & 1.9 & 3.1 & 0.8 & 2 & 2.6 \\
\hline $982^{\circ} \mathrm{C}-4$ Hours & 4.6 & 0.8 & 2.1 & 2.1 & 3.2 & 0.8 & 2.1 & 2.3 & 2.8 & 0.8 & 2.3 & 2.6 \\
\hline $996^{\circ} \mathrm{C}-4$ Hours & 1.9 & 0.7 & 1.8 & 2.7 & 2.3 & 0.8 & 1.9 & 2.7 & 2.5 & 0.7 & 2.1 & 2.5 \\
\hline $1010^{\circ} \mathrm{C}-4$ Hours & 1.1 & 0.7 & 1.8 & 3.3 & 1.1 & 0.7 & 1.9 & 3.2 & 1.1 & 0.8 & 1.8 & 3.8 \\
\hline $1024^{\circ} \mathrm{C}-4$ Hours & 0.1 & 0.6 & 1.7 & 7.4 & 0.2 & 0.6 & 1.6 & 7 & 0.2 & 0.6 & 2.3 & 6.5 \\
\hline
\end{tabular}
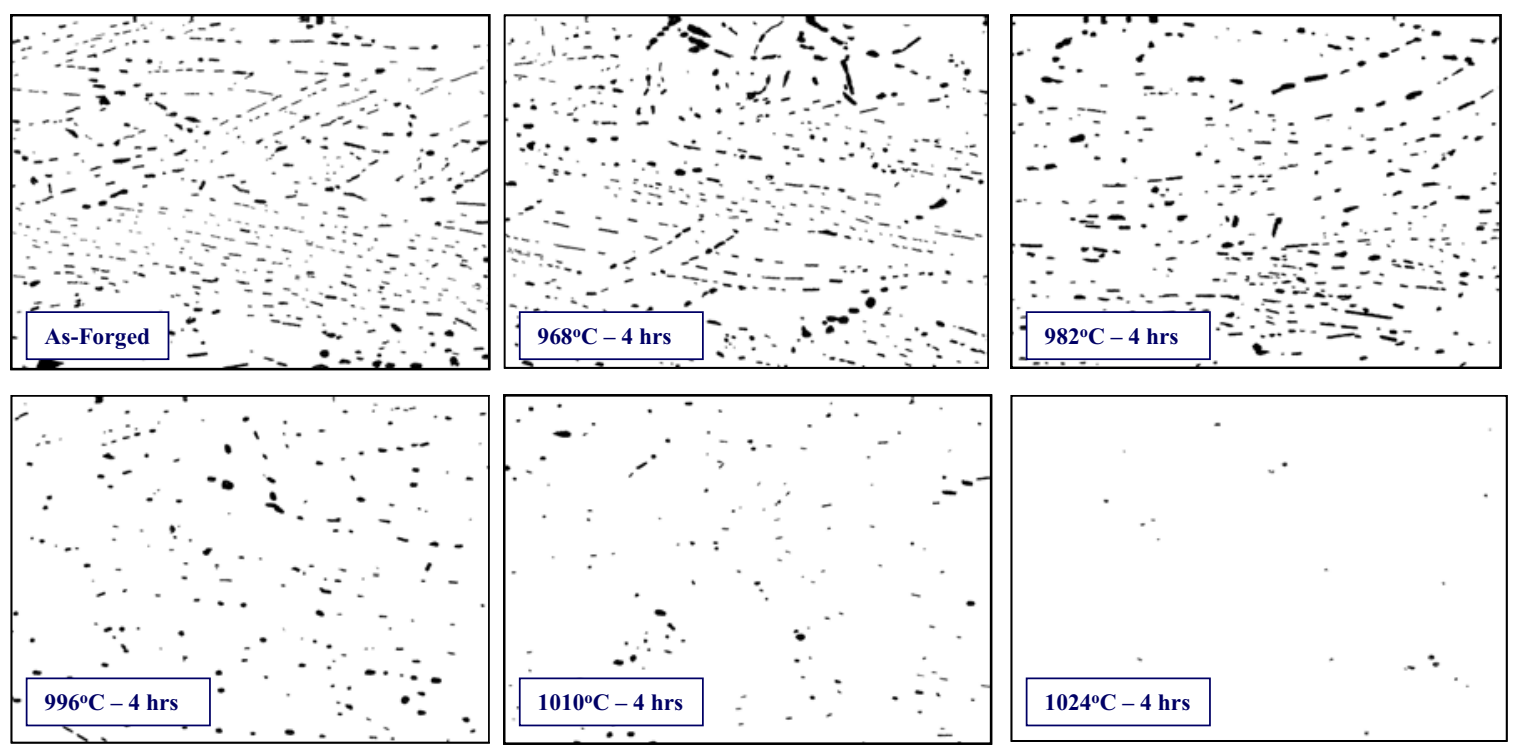

Figure 4. Representative Post Processed SEM Images for $203 \mathrm{~mm}$ Billet

Percent delta and delta inter-particle spacing correlate well with temperature as shown in Figures 5 and 6 . As expected, the percent delta decreases and inter-particle spacing increases as temperature increases. For reference, image analysis was also performed on the as-forged preform prior to GFM conversion. At this stage of manufacture the average $\delta$ was estimated to be $6.2 \%$ which is comparable to the as-forged billet values.

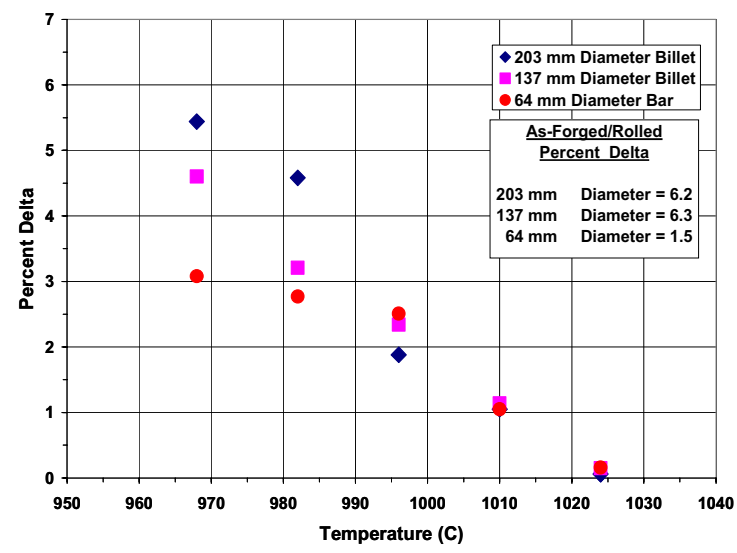

Figure 5. Percent Delta as a Function of Thermal Exposure (4 Hours).

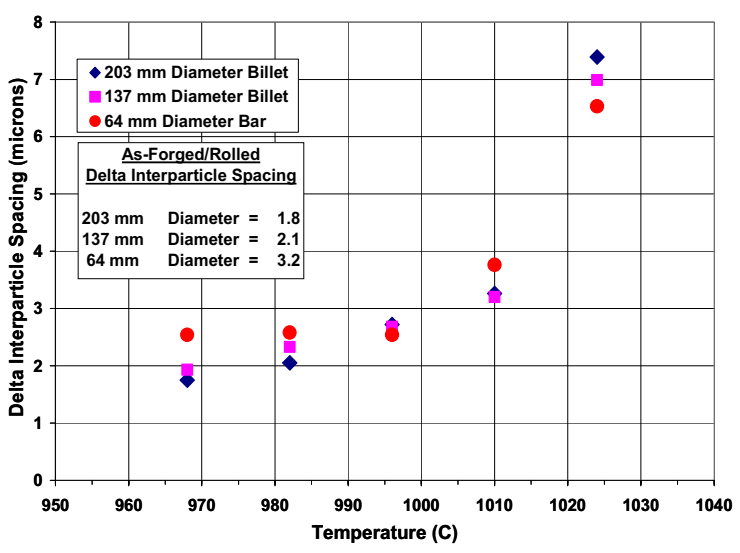

Figure 6. Delta Inter-particle Spacing as a Function of Thermal Exposure (4 Hours). 


\section{Discussion}

After partial conversion of the three $508 \mathrm{~mm} \varnothing$ alloy 718 ingots used for this study, a $\delta$ precipitation heat treatment was performed which results in precipitation of the $\delta$ phase on the (111) planes of the face centered cubic matrix as a continuous or semi-continuous grain boundary phase $[4,5]$. After press forging, the $\delta$ remained acicular and was semicontinuous at both grain and twin boundaries with an estimated volume fraction of $6 \%$. At this stage of manufacture, the grain size was a uniform ASTM 7 from surface to center. Subsequent GFM processing and rolling, however, resulted in differences in both microstructure and thermal exposure response for the three material sizes studied.

In the as-forged or as-rolled condition, all three size materials were fine grain (ASTM $10-$ 11 ) from surface to center. The volume fraction $\delta$, however, was significantly less for the $64 \mathrm{~mm} \varnothing$ rolled bar (1.5\%) when compared to either the $203 \mathrm{~mm} \varnothing$ billet $(6.2 \%)$ or 137 $\mathrm{mm} \varnothing$ billet $(6.3 \%)$. Forge modeling results (Figure 2) indicate that that internal temperatures during GFM processing of the larger diameter billets remained well below the $\delta$ solvus temperature, retaining the high volume fraction of $\delta$ phase observed after initial press breakdown. In addition to the higher furnace temperature for the $64 \mathrm{~mm} \varnothing$ bar, the individual roll stand reductions and rolling speeds generated much adiabatic heating; this resulted in temperatures exceeding the $\delta$ solvus temperature as illustrated in Figure 2. The time above the $\delta$ solvus temperature was sufficient to solution a large portion of the $\delta$ phase, yet retain a fine grain size in the as-rolled condition. The $1.5 \% \delta$ phase for the 64 $\mathrm{mm} \varnothing$ bar in the as-rolled condition, see Table III, is consistent with experimental data reported in the literature for samples removed from a $203 \mathrm{~mm} \varnothing$ billet and exposed to $1100^{\circ} \mathrm{C}$ for three minutes [6].

Differences in response to thermal exposure were observed for the three different material sizes as summarized below:

- Coarsening for $64 \mathrm{~mm} \varnothing$ bar did not occur until $1010^{\circ} \mathrm{C}$. In comparison, both the 137 and $203 \mathrm{~mm} \varnothing$ billets exhibited limited grain growth from $968^{\circ} \mathrm{C}$ through $996^{\circ} \mathrm{C}$. Coarsening was about one grain size (10 to 9) for $203 \mathrm{~mm} \varnothing$ billet compared to about two grain sizes (11 to $9,8 \frac{1}{2}$ ) for $137 \mathrm{~mm} \varnothing$ billet.

- The $137 \mathrm{~mm} \varnothing$ billet exhibited some time dependence for coarsening in the range of $968^{\circ} \mathrm{C}$ to $996^{\circ} \mathrm{C}$. Coarsening was not time dependent over this same range for 203 $\mathrm{mm} \varnothing$ billet.

- A banded duplex structure developed at $1010^{\circ} \mathrm{C}$ for $64 \mathrm{~mm} \varnothing$ with the amount of coarse grains increasing with time of exposure. Duplexing was not observed for the 137 and $203 \mathrm{~mm} \varnothing$ billets, both of which coarsened uniformly.

It can be concluded that differences in thermomechanical processing result in different coarsening behavior during thermal exposure. Variations in temperature during final processing appear to account for the coarsening behavior of the 137 and $203 \mathrm{~mm} \varnothing$ billets relative to $64 \mathrm{~mm} \varnothing$ bar.

Modeling (Figure 2), revealed that the final pass temperatures for 203 and $137 \mathrm{~mm} \varnothing$ billets were more than $100^{\circ} \mathrm{C}$ lower at the center location relative to the $64 \mathrm{~mm} \varnothing$ bar. It is theorized that the higher residual strain in the billet, from colder finishing temperatures, 
may provide sufficient additional energy during thermal exposure to result in grain growth at lower temperatures than for the $64 \mathrm{~mm} \varnothing$ bar. Similarly, the tendency for $137 \mathrm{~mm} \varnothing$ billet to be more prone to coarsening relative to $203 \mathrm{~mm} \varnothing$ billet may be related to the lower internal finish temperature of about $28^{\circ} \mathrm{C}$ for the $137 \mathrm{~mm} \varnothing$ billet. Additional studies are planned to better understand the grain coarsening characteristics, especially for the $137 \mathrm{~mm} \varnothing$ billet.

Image analysis was used to characterize the $\delta$ phase in all three product forms. Within the $1010^{\circ} \mathrm{C}$ to $1024^{\circ} \mathrm{C}$ temperature range, which encompasses the $\delta$ solvus temperature, the $\delta$ phase distribution of all three product forms was similar. With four hour exposures, significant grain size coarsening was observed as the $\delta$ phase approached $1 \%$ and the interparticle spacing exceeded three microns. Grain coarsening was sensitive to time at $1024^{\circ} \mathrm{C}$ resulting in grain sizes of ASTM 4-5.

\section{Conclusion}

Delta processing of alloy 718 material resulted in a uniform ASTM 10 or finer grain size throughout the cross-section of $203 \mathrm{~mm} \varnothing$ billet and $64 \mathrm{~mm} \varnothing$ bar, and a uniform ASTM 11 for $137 \mathrm{~mm} \varnothing$ billet. The as-forged or as-rolled delta distribution and subsequent response to thermal exposure, however, is highly dependent on the thermomechanical processing route. The significantly lower \% delta in the as-rolled $64 \mathrm{~mm} \varnothing$ bar is attributed to adiabatic heating during continuous mill processing. Distribution of $\delta$ phase for all product forms was similar in the $1010^{\circ} \mathrm{C}$ to $1024^{\circ} \mathrm{C}$ temperature range. Also, at $1024^{\circ} \mathrm{C}$, coarsening was sensitive to exposure time. Lower temperature coarsening was observed for the billet material, especially for $137 \mathrm{~mm} \varnothing$; it was not found to be sensitive to time at temperature for $203 \mathrm{~mm} \varnothing$ billet and only slightly time dependent for $137 \mathrm{~mm} \varnothing$ billet. This coarsening may be related to the lower finishing pass temperatures and additional studies are planned to more fully understand this behavior. Understanding the coarsening characteristics of delta-processed 718, in three different product forms, provides information required for planning subsequent forging operations to successfully produce a fine grain product.

\section{References}

1. Carlos Ruiz, Abel Obabueki, and Kathy Gillespie, "Properties of Delta Processed Alloy 718", Superalloys (1992), 33-42.

2. A.W. Dix, J.M. Hyzak, and R.P. Singh, "Application of Ultra Fine Grain Alloy 718”, Superalloys (1992), 23-32.

3. Robert E. Schafrik, Douglas D. Ward, and Jon R. Groh, "Application of Alloy 718 in GE Aircraft Engines: Past, Present and Next Five Years”, Superalloys 718, 625, 706 and Various Derivatives, TMS (2001), 1-11.

4. H.J. Wagner and A.M. Hall, "Physical Metallurgy of Alloy 718", (DMIC Report 217, Batelle Memorial Institute, Columbus, Ohio 43201, 1965).

5. M. Stockinger, E. Kozeschnik, B. Buchmayr and W. Horvath, "Modelling of $\delta$-Phase Dissolution During Preheating of Inconel718 Turbine Disks", Superalloys 718, 625, 706 and Various Derivatives, TMS (2001), 141-148. 
6. H.L. Eiselstein, "Metallurgy of a Columbium Hardened Nickel-Chromium-Iron Alloy", Advances in the Technology of Stainless Steels and Related Alloys, ASTM, (1965), 62-79.

\section{Acknowledgments}

The authors would like to acknowledge Jack Hyzak (ATI Allvac) and Al Dix (GEAE) for their contributions throughout this entire program. Acknowledgment also goes to Ramesh Minisandram (ATI Allvac) for contributions on modeling the billet/bar hot working processes, and to Don Steeves and Josh Tackel (GEAE) for their contributions on image analysis. 